\title{
Research on University Mathematics Experiment in Mathematics Teaching
}

\author{
Xin ZHANG \\ Zhenjiang Watercraft College of PLA \\ Zhenjiang, 212003, China
}

\author{
Yu ZHANG \\ Feixian School, Linyi University \\ Feixian, 273400, China
}

\begin{abstract}
University mathematics teaching should pay attention to the theories contact actual, pay attention to mathematical thought and teaching method, stressed that the new teaching method application into mathematics experiment idea. The paper put forward to reform classroom teaching methods, explore new teaching mode, strengthening the practical teaching of the students, and cultivate students' application and innovation ability. Finally, this paper gives example shows the teaching effect that mathematics experiment combine with university mathematics.
\end{abstract}

Keywords- University mathematics; mathematical experiment; teaching reform; practice; innovation;

\section{INTRODUCTION}

We all know that the physical experiment and chemistry experiment, then what is the mathematics experiment? Long term since, the people understanding to mathematics teaching is the concept, theorem, formula and problem solving. The mathematics teaching in the traditional process is teacher write mathematics formulas on the blackboard, and students in the classroom to listen and do math problem on paper. So, for most students, mathematics discovery activities have not been able to really carry out, enthusiasm to study mathematics had not really been mobilized out.

With the popularization and development of computer, it has changed the traditional way of study mathematics only paper and pen, especially the "four color problem" was a huge influence on the field of mathematics to solve successfully by using the computer, although some mathematicians do not admit this is a proof, i.e. according to mathematical logic inference proof, but the ultimate solution to the problem is to accept the mathematics community.

With the progress of science and technology, especially the rapid development of computer technology, and the role of mathematics influence on contemporary science and even the whole society increasingly significant. Mathematics has become the main pillar of scientific research methods and computing has become indispensable in scientific research means and theory research and scientific experiment. At the same time, the modern mathematics penetrated into almost all disciplines and application areas including management of natural science and the humanities and Social Sciences, economics in. By establishing the mathematical model of Mathematical Model applied mathematics theory and method and combining with the computer to solve practical problems have become extremely common mode. Therefore, mathematical competence and ability of science and technology talents in the society has put forward higher requirements. However, the traditional mathematics curriculum to reflect the problem, cannot reflect the important role of mathematics plays in science and technology and in real life. Therefore appeared like academician Li Daqian pointed out that, the long-term existence of the contradiction phenomena. On the one hand, mathematics is very useful, after on the other hand the students learn mathematics but not with.

About what is mathematical experiment, there is no unified definition. The so-called Mathematical experiment is a mathematical experiment in the modern education theory, especially under the guidance of constructivism learning theory, aims to guide students to understand the mathematical theory of independent exploration in practice process and research abstract mathematics questions and the application of mathematical problem using mathematical software.

Simple, highly integrated mathematical software system can easily carry out symbolic calculus on the mathematical problem or practical problems, numerical calculation and graphic analysis, which can improve the mathematical practical ability, cultivate the spirit of exploration, so as to raise the students' creative ability in the process of practice and exploration. Mathematics experiment requires students more hands-on, multi machine, diligent, explore solutions to practical problems under the guidance of teachers, acquire knowledge through failure and success.

\section{THE TEACHING MODE OF MATHEMATICS EXPERIMENT}

In the mathematical experiment teaching, the block diagram of the teaching mode is as shown in fig. 1.



Fig.1 The process of mathematics experiment 
(1) Presents experimental subject

According to the mathematics experiment teaching content, the teachers put forward mathematics experiment subject. The experimental subject put forward very important, it should not only starting from the problem, but also make the problem is feasible and interest, to attract students to participate in mathematical experiments.

(2) Create the problem situation

The creation of the problem situation is the premise and condition of mathematical experiment teaching, the aim is creating mathematical problem for students' thinking scene, stimulate student's interest in learning.

(3) Determine the experiment scheme

Experimental mathematics teachers select the program modules of mathematical software according to the mathematical experiment content, for students to build a computer experimental platform, demonstrate related command function for students to successfully enter the DIY experiment inquiry. The above three steps is usually composed of experimental mathematics teachers to complete, can be understood as the students mathematical experimental learning, exploring the prelude, time about 50 minutes.

(4) Put forward the personal guess

As a researcher's identity to observe the mathematics phenomenon, found the problem, analyze problems, to solve the question. In this observation, discovery process, students gain perceptual knowledge of mathematics knowledge, training their ability to analyze and solve problems.

(5) Summarize and verify the conjecture

After the experiment operation, the students will be no small harvest. Some of the conclusions are in the default way, make his conjecture is confirmed, the students feel inspired, to experience a sense of achievement. But sometimes there will be a greater contrast with the default conclusion of the situation, the urgent need to clarify the reason which the question produces, at this time the group discussion is very necessary.

(6) The group cooperation and exchanges

This is essential for mathematics experiment teaching link, is also a harvest stage. It provides students with a platform to learn from each other, learn, learn from each other, improve the summary, is to cultivate the students' consciousness of team cooperation spirit, show, individuals and teams provide a stage. Through group cooperation and exchanges, to enable students to fully express their thoughts and feelings, is a concrete manifestation of the students' individuality, is conducive to the formation of harmonious relationship between teachers and students, enhance the class cohesion and centripetal force.

(7) Summary and improvement

Teachers should give a summary evaluation, praise and promotion of experimental scheme is good, give technical guidance for the existing problems, let students in every class have some gains and improve.

(8) Write the experiment report

It contains the following links: experiment, experiment purpose, experiment using the name and version of software, experimental procedures, experimental content, experimental process and results (including the basic steps, the main program list and record of abnormal situations), experience, experimental thinking and experience teacher comments etc..

\section{CASE ANALYSIS OF MATHEMATICS TEACHING EXPERIMENTAL}

[Case] experiment subject: observe change trend of sequence $x_{n}=\left(1+\frac{1}{n}\right)^{n}$ when $n \rightarrow \infty$, and points out its limitations.

[The implement of Mathematics Experimental Teaching]

Step.1 - Observe change trend of sequence $x_{n}=\left(1+\frac{1}{n}\right)^{n}$ when $n \rightarrow \infty$, and points out $\lim _{n \rightarrow \infty}\left(1+\frac{1}{n}\right)^{n}$ limitations.

Step.2. The sequence limit knowledge review:

The definition of the sequence limit: if $n \rightarrow \infty$, sequence $\mathrm{nx} \rightarrow \mathrm{A}$, said constant $\mathrm{A}$ is the limit of $\mathrm{nx}$ sequence when $\mathrm{n}$ $\rightarrow \infty$, denote as $\lim _{n \rightarrow \infty} x_{n}=A$ or $x_{n} \rightarrow A(n \rightarrow \infty)$

Step.3. determine the experiment scheme:

(1) The purpose of the experiment:

1) Understand the definition of sequence limit;

2) To master the method of sequence limit by MATLAB software;

3) Using visualization of Matlab software to observe sequence limit process, enhance conceptual understanding and mastery of limit.

(2) Software and version experiment: Matlab2007a.

(3) Experiments using the command:

Limit (f) \% limit calculation when independent variable tends to 0 ;

Limit ( $\mathrm{F}$, a) \% limit calculation when variables tend to a;

Limit ( $F, N$, a) \% limit calculation when $n$ tends to a;

Limit (F, N, a, 'left') \% left limit calculation when the $n$ tends to a;

Limit (F, N, a, 'right') \% right limit calculation when the $\mathrm{n}$ tends to $\mathrm{a}$;.

(4) The experiment content:

By using the visual function of Matlab software to strengthen the understanding.

(5) Experimental procedures:

The procedure is as follows:

format long

$\mathrm{xn}=1$;

for $\mathrm{n}=1: 30$;

$\mathrm{xn}=(1+1 / \mathrm{n})^{\wedge} \mathrm{n}$;

$\operatorname{plot}\left(\mathrm{n}, \mathrm{xn}, \mathrm{b}^{*}\right.$ ')

grid on;

hold on;

title('The image of $\left.\mathrm{xn}=(1+1 / \mathrm{n})^{\wedge} \mathrm{n} '\right)$;

end

The image is as shown in fig. 2 . 


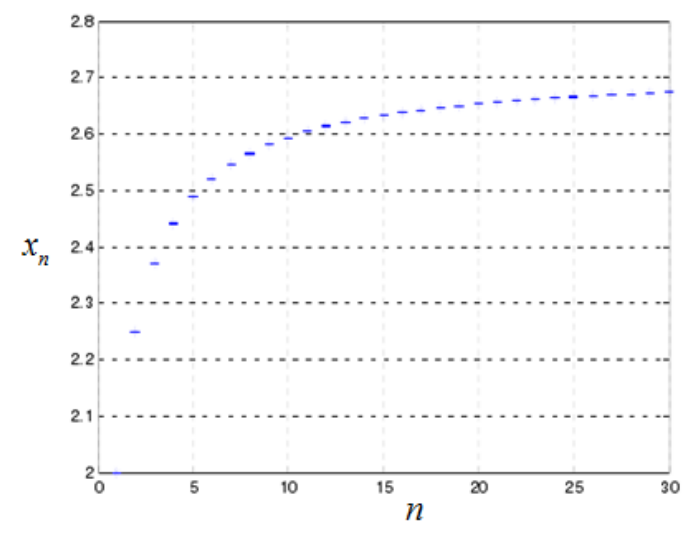

Fig.2 The image of $x_{n}=\left(1+\frac{1}{n}\right)^{n}(\mathrm{n}=1,2, \ldots, 30)$

Step.4. Put forward the personal guess: when $\rightarrow \infty$, $x_{n}=\left(1+\frac{1}{n}\right)^{n} \rightarrow e$

Step.5. Summarize and verify the conjecture:

When $n=1: 100$, The image is shown in figure 3 .

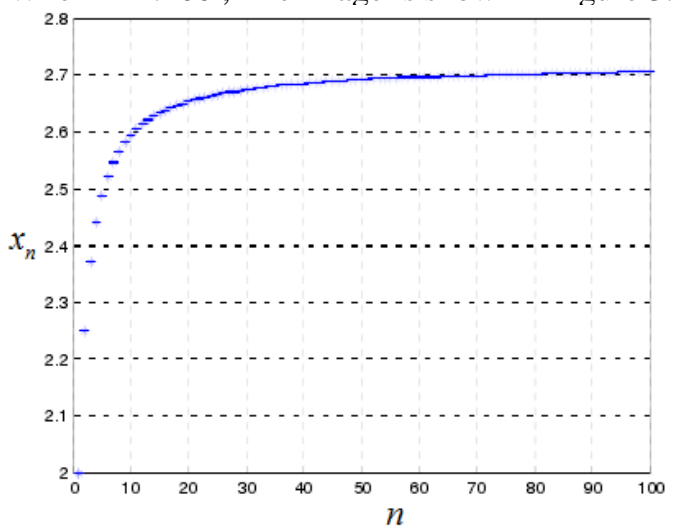

Fig.3 The image of $x_{n}=\left(1+\frac{1}{n}\right)^{n}(\mathrm{n}=1,2, \ldots, 100)$

It as can be seen from the picture, when $\rightarrow$ $\infty, x_{n}=\left(1+\frac{1}{n}\right)^{n} \rightarrow e$

Step.6. The group cooperation and exchanges: when $\mathrm{n}=$ $1: 10000$, the image is shown in figure 4 .

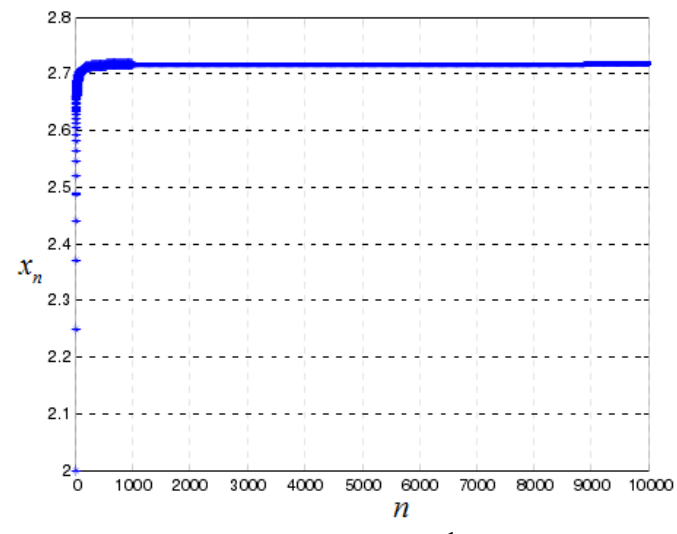

Fig.4 The image of $x_{n}=\left(1+\frac{1}{n}\right)^{n}(\mathrm{n}=1,2, \ldots, 10000)$

Step.7 The teacher summed up to improve:

Based on group cooperation and exchange, the teacher pointed out:

The concept of sequence limit, $\mathrm{n}=100,1000,10000$ It is not big enough, in general, for $\forall \varepsilon>0, \exists N>0$, when $n>N$, always have $|\mathrm{xn}-\mathrm{e}|<\varepsilon$ correct, so, $\lim _{n \rightarrow \infty}\left(1+\frac{1}{n}\right)^{n}=e$

Step.8. Write the experiment report (omitted).

\section{CONCLUSIONS}

Mathematics experiment course is a new thing, it is gradually accepted by schools and professional, it can turn the traditional learning process "teach memory test" into new learning way " intuition - Experiment - error - Thinking guess - proof", make individual dissemination of information into a number of exchange, enable change the passive acceptance information to active learning. Through the mathematical experiment course training, encourage students to use hands and brain thinking and understanding, to give more the opportunity to students. It is an effective attempt of traditional mathematics curriculum teaching reform. With the popularization of mathematics experimental course, its superiority gradually reflected, its role in cultivating talents will be social recognition. These are so that we will further thinking about how mathematics experiment thought into the teaching process in University mathematics.

\section{REFERENCE}

[1] Deng Jianhui. Research on teaching mode of mathematics experiment [J].Middle school mathematics research, 2007 (7)

[2] Zhang Xiaolei. Discuss on educational functions of mathematics experiment [J]. Journal of mathematical education, 2003 (5)

[3] Cao Yiming. Mathematics experiment inquiry teaching [J]. Curriculum teaching materials, 2003 (1)

[4] Li Shangzhi, Chen FaLai. Understanding and practice in constructing the course "mathematics experiment" [J]. Mathematics in practice and theory, 2001 (11)

[5] Wang Mingli. Exploration and practice of experimental teaching of University Mathematics [J]. Journal of XingTai University, 2007 (6)

[6] Yu Dong. Research on the theory and practice of Mathematics Experiment Teaching [J]. Journal of Hubei Radio and TV University, $2006(3)$ 